\title{
Miscibility of Poly(vinyl alcohol)/Poly(methacrylic acid) and Poly(vinyl alcohol)/Poly(acrylic acid) Systems: I. High-Resolution NMR Studies in Solution
}

\author{
Xiaoqing Zhang, ${ }^{*}$ K. TAKegoshi, and Kunio HikichI \\ NMR Laboratory and Department of Polymer Science, Faculty of Science, \\ Hokkaido University, Sapporo 060, Japan
}

(Received August 6, 1990)

\begin{abstract}
Miscibility in two-component polymer systems of poly(vinyl alcohol)/poly(methacrylic acid) (PVA/PMAA) and poly(vinyl alcohol)/poly(acrylic acid) (PVA/PAA) in dimethylsulfoxide (DMSO) solution was examined by high-resolution NMR. Intermolecular NOE was observed between PVA and PMAA or PAA. The results indicate that the PVA and PMAA or PAA are intimately mixed on a scale less than $4 \AA$. The chemical shifts of $\mathrm{COOH}$ resonances of PMAA and PAA and the $\mathrm{OH}$ resonance of PVA suggest the existence of hydrogen-bonding interaction between the two different polymers.

KEY WORDS Poly(vinyl alcohol) / Poly(methacrylic acid) / Poly(acrylic acid) / High-Resolution NMR / Nuclear Overhauser Effect / Polymer Blends / Polymer Complexes / Miscibility / Hydrogen-Bonding Interaction / Proton Chemical Exchange/
\end{abstract}

Polymer blends have been extensively investigated because of their high engineering performance and unique physical properties. Very few polymer pairs mutually interpenetrate at the molecular level to form miscible blends. ${ }^{1}$ The miscibility of two different polymers is enhanced by exothermic intermolecular inteactions such as ion-ion, dipole-dipole, ion-dipole, donor-acceptor, and hydrogen-bonding interactions. These interactions are considered to play key roles in polymer compatibility, and bring about not only homogenous mixing but also unique physical properties. ${ }^{2,3}$ Some of incompatible polymer pairs are successfully mixed at the molecular level by introducing interacting groups. ${ }^{4-8}$ In particular, hydrogen bonding as an important interaction has been investigated extensively from points of view of thermodynamic theory, phase behavior, miscibility, and so on. ${ }^{9-11}$
Poly(vinyl alcohol) (PVA), poly(methacrylic acid) (PMAA), and poly(acrylic acid) (PAA) all have strong hydrogen bonding donor and acceptor groups, and are considered to easily form compatibile blends. Early work showed that when aqueous solutions of PVA and PMAA were mixed, white powder was obtained. The composition of the powder was close to the equimolar ratio of two polymers, even though the initial molar ratio was not equimolar. This fact suggests that the two polymers form a complex due to intermolecular hydrogen bonding between hydroxyl group of PVA and carboxyl group of PMAA. ${ }^{12,13}$ When aqueous solutions of PVA/PAA were mixed, two-phase separation occurred, ${ }^{14,15}$ or clear homogeneous aqueous solution ${ }^{16}$ was obtained according to sample preparation conditions.

\footnotetext{
* On leave from Analytical Center, East China Normal University, Shanghai, P. R. China.
} 
Only relatively recently high-resolution NMR spectroscopy in the liquid state has been applied to explore the interactions and miscibility of polymer blends at the molecular level. ${ }^{17-19}$ Although the morphology in the solid state is lost in solution, the interaction responsible for mixing would still persist. The higher resolution achieved in solution than in the solid state enables us to examine more local and specific interaction on the basis of NMR parameters such as chemical shift, line width, nuclear Overhauser effect (NOE), and so on. Hydrogen bonding can be monitored through the characteristic downfield shift of the resonance of proton participating. ${ }^{20}$ The miscibility of the multicomponent polymers can be estimated through the examination of intermolecular NOE. ${ }^{21}$

Here we wish to present the results of high-resolution NMR study on the interaction behavior of PVA/PMAA and PVA/PAA systems in deuterated-dimethyl sulfoxide (DMSO$\left.d_{6}\right)$ solution. The chemical shift and the line width of proton resonances were examined at various temperatures. NOE experiments were carried out to detect the intermolecular NOE between two different polymers. The results obtained are discussed in terms of the hydrogen-bonding interaction and the miscibility of two polymers in solution. The miscibility of the same systems studied here are also investigated in solid state by the high-resolution CP/MAS NMR method, and the results will be discussed in a subsequent paper.

\section{EXPERIMENTAL}

\section{Samples}

$P V A, P M A A$, and PAA. PVA was kindly provided by Kuraray Co., Ltd. and the molecular weight is 110,000 . PMAA and PAA which were kindly supplied by Nippon Junyaku Co. have molecular weights of 40,000 70,000 and 20,000-40,000, respectively.

PVA/PMAA Systems. Each of PVA and PMAA was dissolved separately in distilled water at a concentration of $0.12 \mathrm{wt} \%$. $\mathrm{pH}$ of all solutions was adjusted to 2 by $2 \mathrm{~N} \mathrm{HCl}$. Two PVA/PMAA mixtures with mixing ratios of $1 / 2$ and $2 / 1$ in monomer-molar were prepared by slowly mixing the two solutions of PVA and PMAA. Powderish solids appeared as soon as the two solutions were mixed. The mixing solutions were stirred at room temperature for $20 \mathrm{~h}$ and subsequently at $333 \mathrm{~K}$ for $4 \mathrm{~h}$, then allowed to stand for $20 \mathrm{~h}$ to precipitate the powder solids completely. The resulting powder samples 1 (PVA/PMAA1) and 2 (PVA/PMAA2) with mixing ratios PVA/ $\operatorname{PMAA}=2 / 1$ and $1 / 2$, respectively, were filtered, washed with cold water, and dried under reduced pressure at $323 \mathrm{~K}$ for 3 days.

The compositions of the two samples of PVA/PMAA1 and PVA/PMAA2 obtained in different mixing ratios of $2 / 1$ and $1 / 2$ were determined from ${ }^{1} \mathrm{H}$ spectra measured in deuterated-dimethyl sulfoxide (DMSO- $d_{6}$ ). It was found that both samples in different mixing ratios have an equimolar composition, i.e., $\mathrm{PVA} / \mathrm{PMAA}=1.1 / 1.0$, as already reported. ${ }^{12,13}$.

PVA/PAA Systems. PVA and PAA in distilled water at $5 \mathrm{wt} \%$ at $\mathrm{pH}=2$ were mixed together in ratios of $2 / 1,1 / 1$, and $1 / 2$ in monomer units at room temperature. No instantaneous precipitation occurred, and clear solutions were obtained. After stirring for about $5 \mathrm{~h}$, the solvent was allowed to evaporate at $313 \mathrm{~K}$ for several days, and transparent films were obtained. The films were dried under reduced pressure at $323 \mathrm{~K}$ for 3 days. These samples are denoted as $\mathrm{PVA} / \mathrm{PAA}=2 / 1$; PVA $/ \mathrm{PAA}=1 / 1$, and PVA $/ \mathrm{PAA}=1 / 2$ according to the respective monomer ratios.

\section{NMR Experiments}

Samples of single component polymers, i.e., PVA, PMAA, PAA, and PVA/PMAA systems, PVA/PAA systems were dissolved in $99.8 \%$ deuterated-dimethyl sulfoxide (DMSO- $d_{6}$ ) at a concentration of $10 \mathrm{wt} \%$. High-resolution NMR experiments were carried out on a JEOL 
JNM-GX270 spectrometer at resonance frequence of $270 \mathrm{MHz}$ for proton $\left({ }^{1} \mathrm{H}\right)$. Proton spectra were observed by the conventional single pulse method with a $90^{\circ}$ pulse width of $18 \mu \mathrm{s}$ and repetition time of $4.5 \mathrm{~s}$. Tetramethylsilane (TMS) was used as an internal chemical shift reference. Temperature was varied from 303 to $403 \mathrm{~K}$ and controlled within $1 \mathrm{~K}$ using a JEOL temperature controller. Proton transient NOE spectra were observed by selective irradiation of the $\mathrm{CH}$ proton resonance of PVA, which was fully presaturated. The radio-frequency field strength for the selective irradiation is about $15 \mathrm{~Hz}$. The mixing time $t_{m}$ ranged from 0.1 to $12 \mathrm{~s}$. NOE difference spectra were obtained by substracting the normal spectrum from corresponding NOE spectrum.

\section{RESULTS AND DISCUSSION}

${ }^{1} \mathrm{H}$ spectra of PVA, PMAA, PAA, PVA/ PMAA1, and PVA/PAA $=1 / 1$ are shown in Figure 1. Peak assignments were based on previous results. ${ }^{22-26}$

\section{NOE Studies of Miscibility}

NOE difference spectra of PVA/PMAA and PVA/PAA systems with different mixing times were measured at various temperatures. The methine proton of PVA was irradiated for all samples. Figure 2 shows the NOE difference spectra of PVA/PMAAl sample and PVA/ $\mathrm{PAA}=1 / 1$ sample with a long mixing time $(12 \mathrm{~s})$ at $303 \mathrm{~K}$. Positive and negative peaks indicate negative and positive NOE, respectively. A positive peak is clearly observed for both samples at methylene protons of PVA. Besides these, significant positive peaks are also observed at resonances of $\mathrm{CH}_{2}, \mathrm{CH}_{3}$, and COOH of PMAA for PVA/PMAA sample and also at resonances of $\mathrm{CH}$ and $\mathrm{COOH}$ of PAA for $\mathrm{PVA} / \mathrm{PAA}=1 / 1$ sample. These results indicate that the intermolecular negative NOE does appear in both PVA/PMAA and PVA/ PAA systems at $303 \mathrm{~K}$.

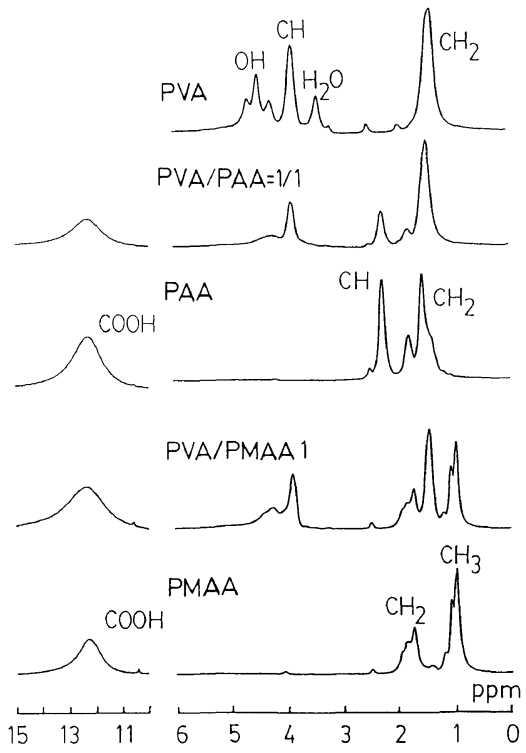

Figure 1. ${ }^{1} \mathrm{H}$ spectra of PVA, PMAA, PAA, PVA PMAA $=1 / 1$, and PVA/PAA $=1 / 1$ samples. The PVA spectrum was observed at $303 \mathrm{~K}$. The high field areas of the spectra of PMAA, PAA, PVA/PMAA = 1/1, and PVA/ PAA $=1 / 1$ were observed at $363 \mathrm{~K}$, and the low-field $\mathrm{COOH}$ spectra were taken at $303 \mathrm{~K}$. The $\mathrm{COOH}$ peaks were magnified to show the weak broad peaks clearly.

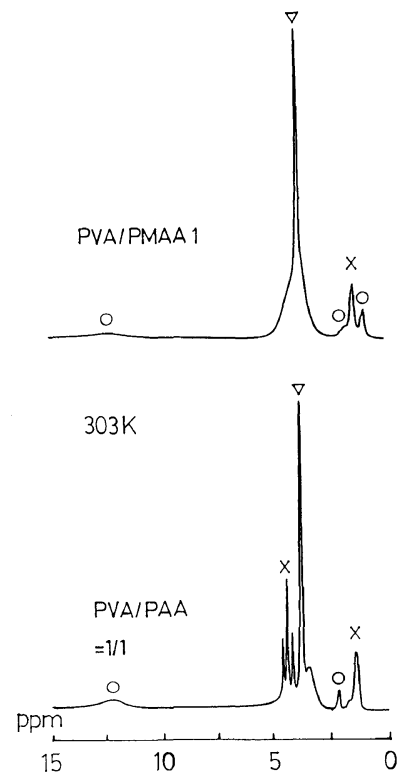

Figure 2. NOE Difference spectra of PVA/PMAA $=1 / 1$ and PVA/PAA $=1 / 1$ samples at $303 \mathrm{~K}$ in DMSO- $d_{6}$ solution. Marks" $x$ " and " $\bigcirc$ " represent intramolecular and intermolecular NOEs, respectively. The " $\nabla$ " proton was irradiated. 


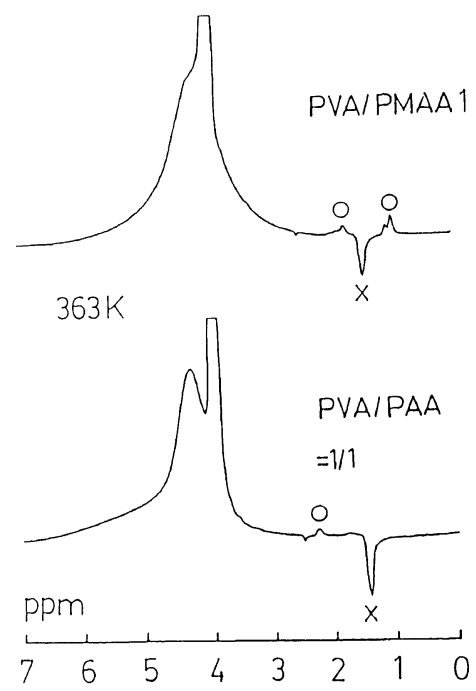

Figure 3. NOE Difference spectra of PVA/PMAA $=1 / 1$ and PVA $/ \mathrm{PAA}=1 / 1$ samples at $363 \mathrm{~K}$ in DMSO- $d_{6}$ solution. Marks " $x$ " and " $\bigcirc$ " represent intramolecular and intermolecular NOEs, respectively. Broad $\mathrm{COOH}$ peaks are not shown here.

At $363 \mathrm{~K}$, intramolecular and intermolecular NOEs are also observed as shown in Figure 3. At this temperature a positive NOE is observed for $\mathrm{CH}_{2}$ resonance of PVA in both PVA/ PMAA and PVA/PAA systems. On the other hand, PMAA or PAA resonances show negative NOEs.

Figure 4 shows the mixing time dependence of the intensity of NOE difference spectra for $\mathrm{CH}_{2}$ peak of PVA and $\mathrm{CH}_{3}$ peak of PMAA of PVA/PMAA1 sample at $303 \mathrm{~K}$ (upper) and $363 \mathrm{~K}$ (lower). At $303 \mathrm{~K}$ the positive peaks of $\mathrm{CH}_{2}$ of PVA and $\mathrm{CH}_{3}$ of PMAA increase in intensity as the mixing time increases. At mixing times longer than about $1 \mathrm{~s}$, the intensities of these peaks remain unchanged with further increase of mixing time. At $363 \mathrm{~K}$, the intensities of the positive peak of $\mathrm{CH}_{3}$ resonance of PMAA and the negative peak of $\mathrm{CH}_{2}$ resonance of PVA become constant when the mixing time reaches $2 \mathrm{~s}$. Since the intensity of NOE signal would either increase or decrease depending on the correlation time of motion which is sensitive to temperature, we observe

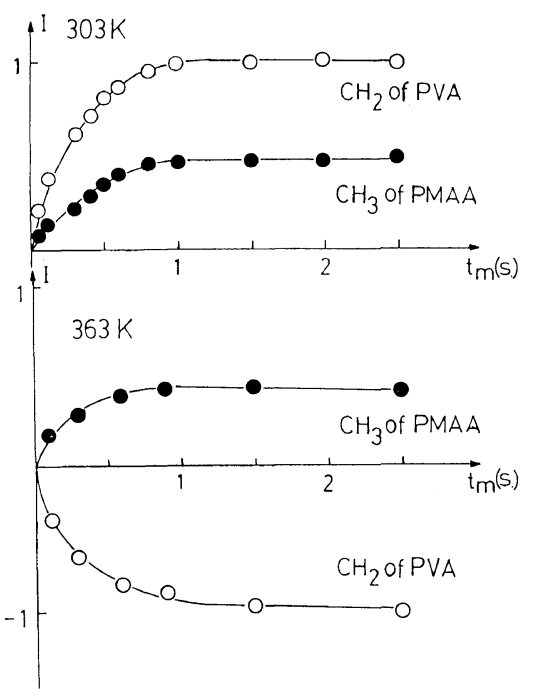

Figure 4. Mixing time $\left(t_{m}\right)$ dependence of the intensity of NOE difference spectra of PVA/PMAA $=1 / 1$ sample in DMSO- $d_{6}$ solution at $303 \mathrm{~K}$ (upper) and $363 \mathrm{~K}$ (lower).

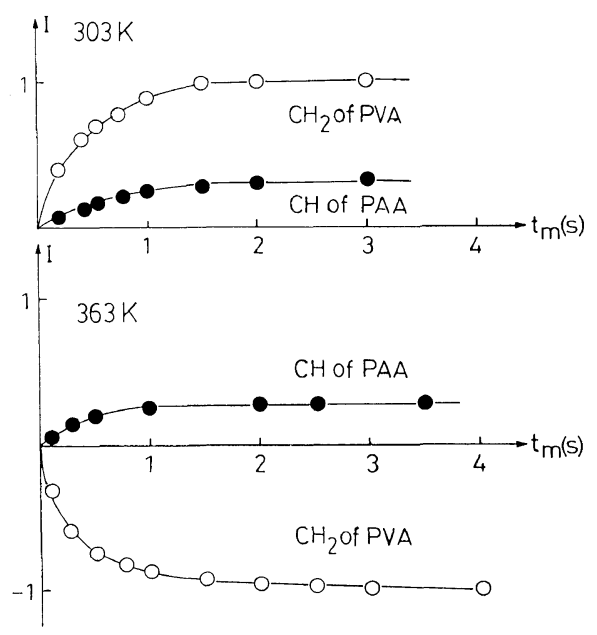

Figure 5. Mixing time $\left(t_{m}\right)$ dependence of the intensity of the NOE difference spectra of PVA/PAA $=1 / 1$ sample in DMSO- $d_{6}$ solution at $303 \mathrm{~K}$ (upper) and $363 \mathrm{~K}$ (lower).

the negative intramolecular NOE at lower temperatures, while positive NOE at higher temperatures for PVA. Almost the same mixing time dependences of intensities of $\mathrm{CH}_{2}$ peaks of PVA and $\mathrm{CH}$ peak of PAA for PVA/ $\mathrm{PAA}=1 / 1$ system in NOE difference spectra were observed and are shown in Figure 5. 
Table I. NOE for PVA/PMAA and PVA/PAA systems in DMSO- $d_{6}$ at three different temperatures ${ }^{\mathrm{a}}$

\begin{tabular}{|c|c|c|c|c|c|c|}
\hline & \multicolumn{2}{|c|}{ PVA/PMAAl } & \multicolumn{2}{|c|}{$\mathrm{PVA} / \mathrm{PAA}=1 / 1$} & \multicolumn{2}{|c|}{$\mathrm{PVA} / \mathrm{PAA}=1 / 2$} \\
\hline & $\begin{array}{c}\mathrm{CH}_{2} \\
\text { of PVA }\end{array}$ & $\begin{array}{c}\mathrm{CH}_{3} \\
\text { of PMAA }\end{array}$ & $\begin{array}{c}\mathrm{CH}_{2} \\
\text { of PVA }\end{array}$ & $\begin{array}{c}\mathrm{CH} \\
\text { of PAA }\end{array}$ & $\begin{array}{c}\mathrm{CH}_{2} \\
\text { of PVA }\end{array}$ & $\begin{array}{c}\mathrm{CH} \\
\text { of PAA }\end{array}$ \\
\hline $303 \mathrm{~K}$ & $-18 \%$ & $-11 \%$ & $-12 \%$ & $-8.9 \%$ & $-14 \%$ & $-15 \%$ \\
\hline $323 \mathrm{~K}$ & $-6.5 \%$ & $-7.3 \%$ & $-2.8 \%$ & $-4.2 \%$ & $-6.1 \%$ & $-7.5 \%$ \\
\hline $363 \mathrm{~K}$ & $+3.1 \%$ & $-2.6 \%$ & $+2.8 \%$ & $-2.0 \%$ & $+0.8 \%$ & $-1.1 \%$ \\
\hline
\end{tabular}

a The positive and negative percentages indicate positive and negative NOEs.

NOE values were evaluated from the NOE difference spectra and are listed in Table I. The positive and negative percentages indicate positive and negative NOEs. As the temperature increases, both intramolecular and intermolecular negative NOEs decrease. For the $\mathrm{CH}_{2}$ peak of PVA at $363 \mathrm{~K}$, the peak even appears as negative in all samples, indicating positive intramolecular NOE. The intramolecular and intermolecular NOE are appreciable for both PVA/PMAA and PVA/PAA systems in the temperature range studied.

It has been established that NOE depends on the sixth power of the inverse of the inter-proton distance, the effective correlation time governing reorientation of the interproton vector, and the mixing time. Interproton distances greater than $4 \AA$ would be too far to bring about appreciable NOE. For example, for poly(vinyl methyl ether)/polystyrene blends, the blends are miscible in toluene solution and show intermolecular NOE, but no intermolecular NOE can be observed for the heterogeneous system in chloroform solution. ${ }^{19}$ The present NOE results of PVA/ PMAA and PVA/PAA systems suggest that the two different polymers are close enough to bring about significant intermolecular NOE.

Figures 4 and 5 also reflect the intramolecular and intermolecular spin-diffusion rates. Assuming a single correlation time, the interproton distance has the relation with the cross-relaxation rate $\operatorname{as}^{27-29}$ :

$$
\left(d_{i j} / d_{k l}\right)^{1 / 6}=\left(r_{k l} / r_{i j}\right)
$$

where $d_{i j}\left(d_{k l}\right)$ and $r_{i j}\left(r_{k l}\right)$ are the interproton distance and cross-relaxation rate between $i(k)$ and $j(l)$, respectively. It is found that the intermolecular cross-relaxation rate between two different polymers is quite similar to the intramolecular one at lower temperatures. The results suggest that the time-averaged proton distance between two different polymers should be similar to that between methine proton and methylene proton of PVA at lower temperatures. Assuming that the carbon-carbon, carbon-hydrogen bond lengths, and the $\mathrm{C}-\mathrm{C}-\mathrm{H}$ angle of PVA are $1.54 \AA .1 .20 \AA$, and $109.5^{\circ}$, respectively, ${ }^{30}$ the time-averaged distance between methine and methylene protons of PVA is about $2.7 \AA$. The proton distance between two different polymers should be similar to this value.

\section{Temperature Dependence of $\mathrm{COOH}$ and $\mathrm{OH}$ Resonances}

The ${ }^{1} \mathrm{H}$ spectra of PVA, PMAA, PAA, PVA/PMAA, and PVA/PAA systems were measured at various temperatures from 303 to $403 \mathrm{~K}$. It was found that the resonances of $\mathrm{CH}$, $\mathrm{CH}_{2}$, and $\mathrm{CH}_{3}$ protons of PVA, PMAA, and PAA do not show remarkable chemical shift change with increasing temperature, although the line widths become narrower. On the other hand, the resonances of $\mathrm{COOH}$ protons of PMAA and PAA and the resonance of $\mathrm{OH}$ proton of PVA show noticeable change in chemical shift as well as line width with 


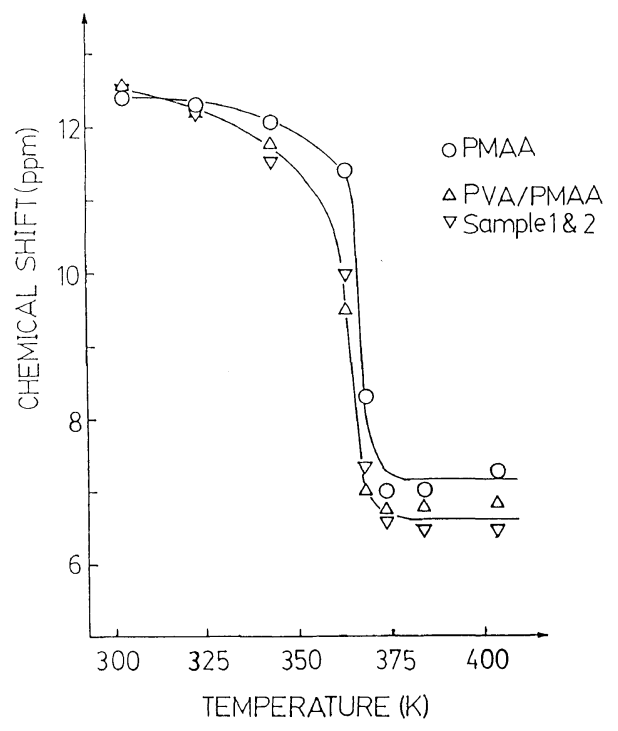

Figure 6. The temperature dependence of chemical shift of the $\mathrm{COOH}$ peaks of pure PMAA $(\mathrm{O})$, PVA/PMAA = $1 / 1$ complexes $1(\triangle)$ and $2(\nabla)$.

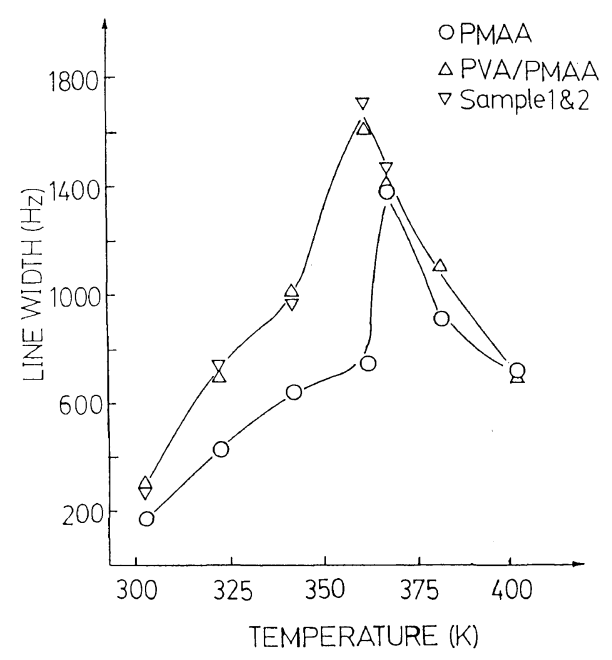

Figure 7. The temperature dependence of line width of the $\mathrm{COOH}$ peaks of pure PMAA (O), PVA/PMAA = $1 / 1$ complexes $1(\triangle)$ and $2(\nabla)$.

increasing temperature. The temperature dependence of the chemical shift of $\mathrm{COOH}$ protons for pure PMAA and PVA/PMAA systems are shown in Figure 6. Figure 7 shows the temperature dependence of the line widths of these resonances. The temperature de-

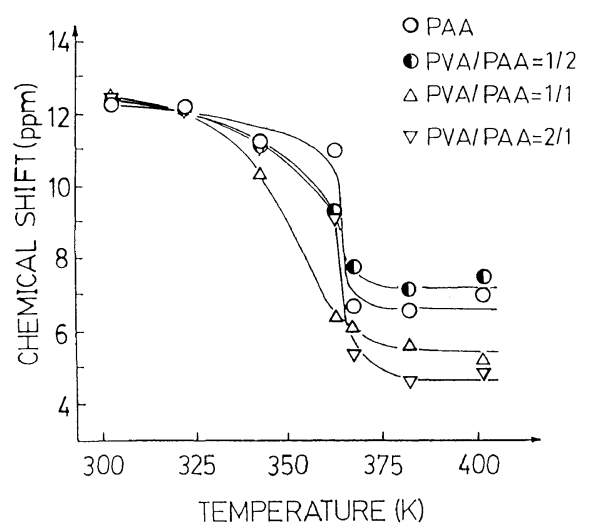

Figure 8. The temperature dependence of the chemical shift of the $\mathrm{COOH}$ peaks of pure PAA and PVA/PAA

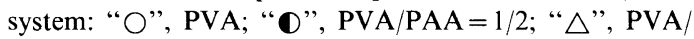
PAA $=1 / 1 ; " \nabla "$, PVA/PAA $=2 / 1$.

pendence of the chemical shift of $\mathrm{COOH}$ protons for pure PAA and PVA/PAA systems is also shown in Figure 8.

The resonances of $\mathrm{COOH}$ proton of pure PMAA appear at very low-fields of about $12 \mathrm{ppm}$ at lower temperatures. With increasing temperature, the $\mathrm{COOH}$ resonance of PMAA shifts to higher fields, and shows a sudden up-field shift to about $7 \mathrm{ppm}$ in the vicinity of $370 \mathrm{~K}$ above which temperature the chemical shift levels off. With the sudden up-field shift, line broadening occurs as shown in Figure 7. Maximum line broadening was observed at about $360 \mathrm{~K}$.

The temperature dependences of chemical shift and the line width of the $\mathrm{COOH}$ protons of PMAA or PAA components are similar for the PVA/PMAA and PVA/PAA systems. However, some differences of the spectra between that of pure PMAA, PAA and two-polymer systems are still noticeable. At the lowest temperature ( $303 \mathrm{~K}$ ) studied, the $\mathrm{COOH}$ proton resonance of PMAA component in PVA/PMAA system shows an additional downfield shift about $0.1-0.2 \mathrm{ppm}$ as compared to that of pure PMAA. Such additional downfield shift of the $\mathrm{COOH}$ resonance was also observed for PVA/PAA samples.

At higher temperatures, however, the $\mathrm{COOH}$ 


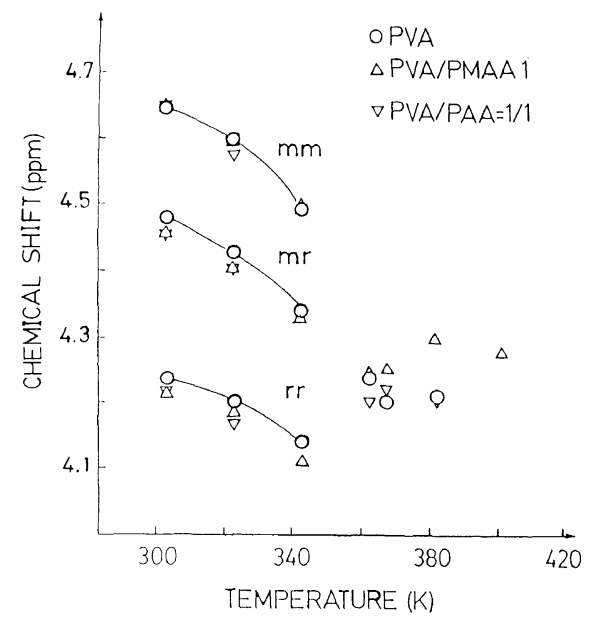

Figure 9. The temperature dependence of chemical shift of the $\mathrm{OH}$ peaks of pure PVA $(\mathrm{O})$, and PVA/PMAA = $1 / 1(\triangle)$ and PVA/PAA $=1 / 1(\nabla)$ samples. " $m m "$, " $m r$ " and " $r r$ " indicate triad sequences.

resonance appears at $0.5-1 \mathrm{ppm}$ upfield relative to that of pure PMAA or PAA. For PVA/PAA systems, the $\mathrm{COOH}$ resonance appears at higher fields with increasing PVA concentration as seen in Figure 8. Figure 9 shows the temperature dependence of the chemical shift of $\mathrm{OH}$ proton resonance for pure PVA, PVA/PMAA1 sample and PVA/PAA = $1 / 1$ sample. The resonances move to upfield as temperature increases with significant linebroadening which masks the triad tacticity splitting above $340 \mathrm{~K}$.

Since the systems studied here consist of three components, PMAA or PAA, PVA, and DMSO, hydrogen-bonding interaction would occur between a polymer and DMSO, between polymers of the same kind, and between two different kinds of polymers, i.e., PMAA or PAA and PVA. Usually the protons participating in hydrogen bonding at low temperatures shift downfield. At high temperatures the protons become labile, and hydrogen bonding would be broken, leading to a upfield shift. Thus, as temperature increases, dynamic chemical exchange of the protons involved in hydrogen bonding occurs. Intermediate exchange rate causes line broadening, while fast exchange causes line narrowing. For the fast exchange between two different states, the resonance appears at an average chemical shift position of the two.

For pure PMAA and PAA below $350 \mathrm{~K}$, the appearance of $\mathrm{COOH}$ protons at very low fields is probably indicative of the hydrogen bonding with DMSO. Above $350 \mathrm{~K}$, hydrogen bonds begin to be destroyed, and the peak of $\mathrm{COOH}$ proton moves to upfield with line broadening due to intermediate proton exchange. Above $360 \mathrm{~K}$, hydrogen bonds are almost broken and proton exchange is so fast that the line becomes narrower. A similar situation occurs for $\mathrm{OH}$ protons of PVA for pure PVA, PVA/PMAA and PVA/PAA systems.

Although the chemical shift values of $\mathrm{COOH}$ protons are explained by taking account of the hydrogen bonding, the sudden upfield shift in the vicinity of $370 \mathrm{~K}$ is yet not fully understood. One of the possible explanations may be the conformational change of PMAA or PAA in DMSO in the vicinity of $370 \mathrm{~K}$. Work is currently in progress.

For PVA/PMAA and PVA/PAA systems at $303 \mathrm{~K}, 0.1-0.2 \mathrm{ppm}$ additional downfield shift of $\mathrm{COOH}$ protons as compared to pure components might be attributed to hydrogen bonding between PVA and PMAA or PAA, although it is not significant as compared to a line width of about $270 \mathrm{~Hz}(1 \mathrm{ppm})$. In DMSO solution, such hydrogen bonding between different polymers is only appreciable at lower temperatures. On the other hand, 0.5-1 ppm additional upfield shift of $\mathrm{COOH}$ protons in PVA/PMAA or PVA/PAA systems observed at higher temperatures would be determined by hydrogen-bonding interactions and proton exchange of $\mathrm{COOH}$ and $\mathrm{OH}$. Since $\mathrm{OH}$ protons of pure PVA resonates at $4.2-4.3 \mathrm{ppm}, \mathrm{COOH}$ resonance would move to higher fields as the concentration of PVA increases under conditions of fast exchange between $\mathrm{OH}$ protons of PVA and $\mathrm{COOH}$ protons of PAA at higher temperatures.

The ${ }^{13} \mathrm{C}$ spectra of the systems studied here 
were also examined. In the temperature region from $303 \mathrm{~K}$ to $403 \mathrm{~K}$, an upfield shift of $1 \mathrm{ppm}$ was also observed for $\mathrm{COOH}$ carbon resonances of both PMAA and PAA due to the dissociation of hydrogen bonding between the polymers and solvent. There is no remarkable difference in the spectra between pure polymers and the two-component systems. The ${ }^{13} \mathrm{C}$ spectra seem unsuitable to study intermolecular interactions in solution.

In summary, it is concluded that for PVA/PMAA and PVA/PAA systems in DMSO solution, PVA and PMAA or PAA are miscible on a scale less than $4 \AA$ due to the hydrogen-bonding interaction.

Acknowledgments. Xiaoqing Zhang is a recipient of the scholarship for foreign students from the Japanese Government. This work was supported by Grants-in-Aid from the Ministry of Education, Science, and Culture of Japan (Grant No. 02554014 and 02750623). We are also grateful to Mr. S. Tsuda and Mr. A. Asano for their kind help in NMR experiments.

\section{REFERENCES}

1. D. Paul and S. Newman, "Polymer Blends," Academic Press, New York, 1978.

2. O. Olabisi, L. Robeson, and M. Shaw, "Polymer-Polymer Miscibility," Academic Press, New York, 1979.

3. D. J. Walsh and S. Rostami, Adv. Polym. Sci., 70, 119 (1985).

4. E. M. Pearce, T. K. Kwei, and B. Y. Min, J. Macromol. Sci.-Chem., A21, 1181 (1984).

5. D. Kotzev, E. M. Pearce, and T. K. Kwei, J. Appl. Polym. Sci., 29, 4443 (1984).

6. A. Eisenberg and M. Hara, Polym. Eng. Sci., 24, 1306 (1984).

7. M. Hara and A. Eisenberg, Macromolecules, 17, 1335 (1984).
8. H. Kim, E. M. Pearce, and T. K. Kwei, Macromolecules, 22, 3374 (1984).

9. P. C. Painter, Y. Park, and M. M. Coleman, Macromolecules, 22, 570 (1989); ibid., 22, 580 (1989).

10. M. M. Coleman, D. J. Skrovanek, J. Hu, and P. C. Painter, Macromolecules, 21, 59 (1988).

11. E. J. Moskala, D. V. Varnell, and M. M. Coleman, Polymer, 26, 228 (1985).

12. I. S. Ohkrimenko and E. B. D'yakonova, Vysokomol. Soyed. in Ser. A., 6, 1891 (1964).

13. G. I. Distler, E. B. D'yakonova, I. F. Yefremov, Ye. I. Kortukova, I. S. Okhrimenko, and P. S. Sotnikov, Vysokmol. Soyedin., Ser. A., 8, 1737 (1966).

14. L. J. Hughes and G. E. Britt, J. Appl. Polym. Sci., 5, 337 (1961).

15. G. R. Williamson and B. Wright, J. Polym. Sci., A, 3, 3887 (1965).

16. T. Q. Nguyen, A. Essamri, R. Clement, and J. Neel, Makromol. Chem., 188, 1973 (1987).

17. A. Natansohn and A. Eisenberg, Macromolecules, 20, 323 (1987)

18. P. A. Mirau, H. Tanaka, and F. A. Bovey, Macromolecules, 21, 2929 (1988).

19. M. W. Crowther, I. Cabasso, and G. C. Levy, Macromolecules, 21, 2924 (1988).

20. J. A. Pople, W. G. Schneider, and H. J. Bernstein, "Highresolution Nuclear Magnetic Resonance," McGraw-Hill, New York, Toronto, and London, 1959.

21. J. H. Noggle and R. E. Schirmer, "The Nuclear Overhauser Effect," Academic Press, New York and London, 1971.

22. T. Moritani, I. Kurama, K. Shibatani, and Y. Fujiwara, Macromolecules, 5, 577 (1972).

23. K. Hikichi and M. Yasuda, Polym. J., 19. 1003 (1987).

24. E. Klesper, A. Johnsen, and W. Gronski, J. Polym Sci., Polym. Lett. Ed., 8, 369 (1970).

25. J. Schriever and J. C. Leyte, Polymer, 18, 1185 (1977).

26. J. Schaefer, Macromolecules, 4, 98 (1971).

27. C. M. Dobson, E. T. Olejniczak, F. M. Poulsen, and R. G. Ratcliffe, J. Magn. Reson., 48, 97 (1982).

28. J. W. Keepers and T. L. Janes, J. Magn. Reson., 57, 404 (1984).

29. G. M. Clore and A. M. Gronenborn, J. Magn. Reson., 61, 158 (1985)

30. Y. Inoue, A. Nishioka, and R. Chujo, J. Polym. Sci., Polym. Phys. Ed., 11, 2237 (1973). 